\title{
Resectable Small Intestinal Carcinoma
}

National Cancer Institute

\section{Source}

National Cancer Institute. Resectable Small Intestinal Carcinoma. NCI Thesaurus. Code C8639.

Carcinoma of the small intestine amendable to resection. 